\title{
Diversity and density of butterfly communities in urban green areas: an analytical approach using GIS
}

\author{
Cheol Min Lee ${ }^{1^{*}}$, Jin Wook Park², Tae-Sung Kwon³ ${ }^{3}$ Sung-Soo Kim, Jae Won Ryu ${ }^{5}$, Seung Jae Jung ${ }^{6}$ \\ and Sun Kyung Lee ${ }^{7}$
}

\begin{abstract}
Background: Urbanization is one of the leading causes of habitat loss, habitat degradation, and fragmentation. Urban development negatively affects biodiversity. We clarified changes in butterfly communities due to urbanization in urban green areas.

Results: In total, 59 species and 1,465 individuals of butterflies were observed in the four urban green areas - Namsan Park (NS), Ewha Womans University (EW), Bukseoul Dream Forest (BD), and Hongneung Forest (HF) - and a natural forest, Gwangneung Forest (GF). The categories of land use around the study sites were determined based on GIS data. Species richness and density of niche breadth and habitat type in the four urban green areas differed mostly from those in GF. Estimated species richness and species diversity $\left(H^{\prime}\right)$ in the four urban green areas were significantly lower than those in GF. Species richness and density of forest interior species and specialist species were positively correlated with paddy, field, and forest, whereas those of forest interior species and specialists were negatively correlated with urban area and road. Species composition and community structure of butterflies in the four urban were differed from those in GF.

Conclusions: These results suggest that decreases in paddy, field, and forest associated with the increased urban area and road negatively influenced species composition and changed butterfly communities.
\end{abstract}

Keywords: Butterfly; Urbanization; Urban green area; GIS

\section{Background}

Urbanization is usually considered to impact biodiversity (Blair and Launer 1997; McKinney 2002, 2006, 2008; Bergerot et al. 2011). Cities are generally grown in terms of human population size over time (Grimm et al. 2008). This growth is accompanied by an expansion of urban areas. Changes in habitat quality and quantity associated with urbanization have negative influences on biodiversity. Plants and animals have frequently experienced local extinction in urban area due to habitat loss, habitat degradation, and fragmentation (McKinney 2002; Clark et al. 2007). Studies on the effects of urbanization on biodiversity in urban areas compared with rural areas

\footnotetext{
* Correspondence: leecheolmin77@gmail.com

'Division of Forest Ecology, Korea Forest Research Institute, 57 Hoegi-ro, Dongdaemun-gu, Seoul 130-712, Republic of Korea

Full list of author information is available at the end of the article
}

have shown different species compositions and less abundance of organisms: e.g., mammals (George and Crooks 2006), amphibians (Osawa and Katsuno 2005; Hamer and McDonnell 2008), birds (Motegi and Yanai 2005; Rubèn and Ian 2009), ground beetles (Niemelä et al. 2002; Lee and Ishii 2009; Lee and Kwon 2013), ants (Yamaguchi 2005; Lee and Kwon 2013), and butterflies (Imai 2004; Lee and Kwon 2012; Bergerot et al. 2011).

Butterflies are a useful bio-indicator because they can be readily surveyed, and they react rapidly to environmental changes due to their short generation time, high mobility, and specific habitat preferences (Clark et al. 2007; Lee et al. 2014). Butterflies are also well known both taxonomically and ecologically (Honda and Kato 2005; Kim et al. 2011). Butterfly communities are greatly affected by vegetation changes because most butterfly larvae have strong associations with host plants, and adults require a specific 
range of nectar plants (Thomas 1995; Honda and Kato 2005). Butterflies are known to respond sensitively to the effects of urbanization (Clark et al. 2007; Lee and Kwon 2012; Lizée et al. 2012). An increase in urban features, such as buildings, roads, and population growth, correspond to a decreases in butterfly species richness, diversity, and abundance (Ruszczyk and De Araujo 1992; Blair and Launer 1997; Stefanescu et al. 2004; Dover and Settele 2009). Most butterfly studies on urbanization have investigated environmental variables using qualitative methods, aerial photographs, or Landsat TM data (Ishii et al. 1991; Kitahara and Fujii 1994, 1997; Blair and Launer 1997; Imai 2004; Mauro et al. 2007). However, a GIS method can more concretely analyze the land use conditions. Changes in environmental factors due to urbanization can be evaluated using a GIS method.

Since the 1960s, Korea has urbanized rapidly with economic development and the population growth concentrated in the cities (Kim 2008). Seoul, the capital, is the most urbanized area. Metro Seoul is divided into north and south by the Hangang River. Seoul is surrounded by Mt. Bukhan-san, Mt. Sulak-san, Mt. Kwanak-san, Mt. Cheongryang-san, and Mt. Cheoma-san. Recently, about $46.3 \%$ of the Korean population lives in Seoul and the greater metro capital area (Lee 2003). Most areas in Seoul are comprised of houses, apartments, and other buildings. However, there are also large urban green areas, such as ancient palace gardens, university campuses, urban parks, urban forests, and arboretums are scattered around Seoul. Urban green areas remained like green islands separated from other surrounding natural areas. Urban green areas play an important role in urban environments as habitats for organisms as well as recreational areas for humans (McKinney 2008). Urban green areas with significant ecological value should be protected and managed to maintain biodiversity and recreational value.

In this study, we explored the relationships between butterfly diversity and environmental variables based on GIS. Specifically, we sought to answer three questions. (1) How does the butterfly community in an urban green area differ from that in a natural forest? (2) Which species are more vulnerable to the effects of urbanization? (3) Which environmental factors influence (positively or negatively) the butterfly communities? Finally, we suggest an alternative to increase butterfly diversity in urban areas.

\section{Methods}

\section{Study sites}

We chose four urban green areas and one natural forest as a control (Figure 1). Namsan Park, Bukseoul Dream Forest, and Hongneung Forest are surrounded by apartment complexes, residential areas, and roads. Ewa Womans University is located near to natural forests. Gwangneung forest, a natural forest, is one of the most protected forests in Korea.

Namsan Park (NS: N $37^{\circ} 33^{\prime}$, E $126^{\circ} 59^{\prime}$ ) is a mountain that symbolizes Seoul. NS is one of the most famous

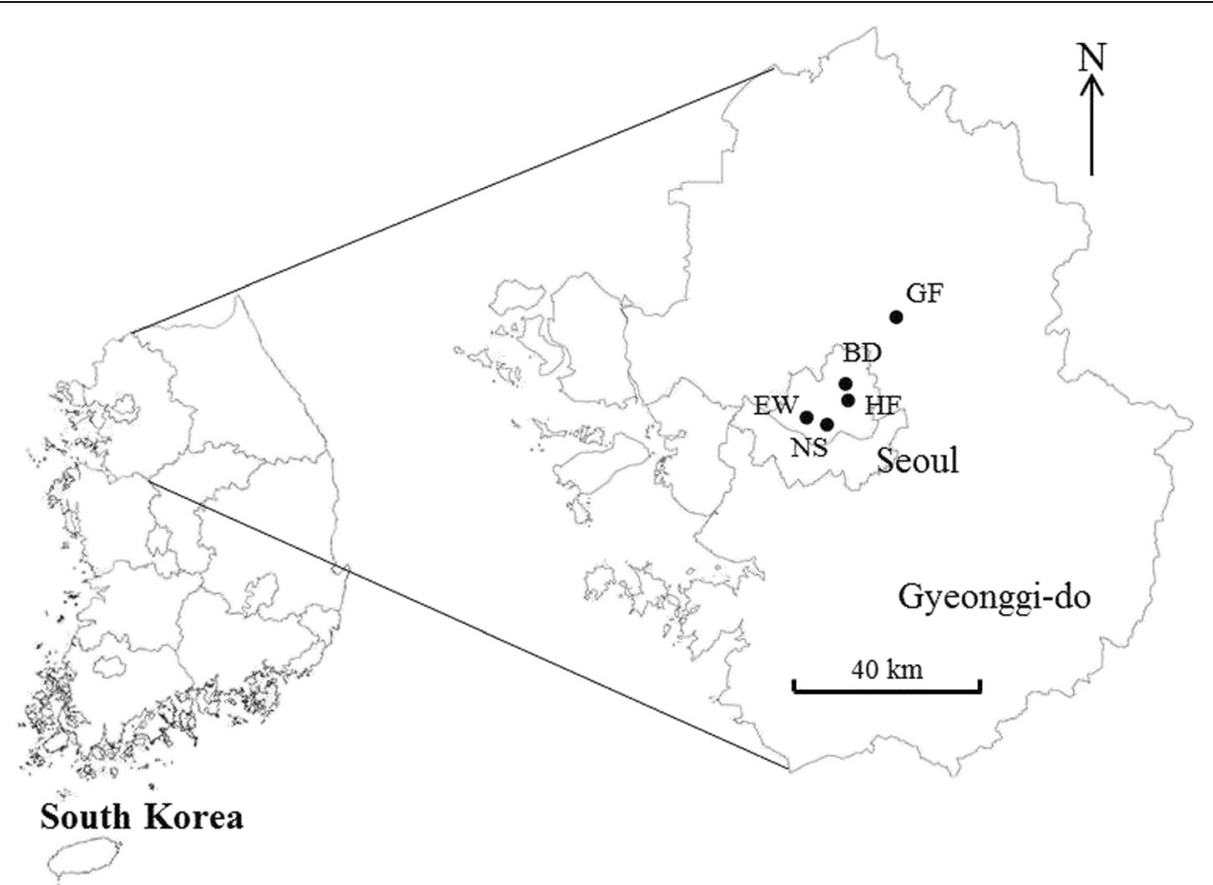

Figure 1 Map of the study sites. NS, Namsan Park; EW, Ewha Womans University; BD, Bukseoul Dream Forest; HF, Hongneung Forest; GF, Gwangneung Forest. 
urban parks in Seoul, largely because of the N Seoul Tower $(236.7 \mathrm{~m})$. It is located in the heart of Seoul, hanging over Jung-gu and Yongsan-gu. About 10,000 people visit during the slow season and 30,000 during the peak season. In total, 552 species (191 woody plants, 361 herbaceous plants) belonging to 85 families grow on 103 ha (Parks of Seoul 2014). Broadleaf trees account for $76.6 \%$ and needle-leaf trees, like pine trees and pine nut trees, account for $23.3 \%$. The major tree species are Quercus mongolica, Robinia pseudoacacia, and Prunus serrulata var. spontanea (Parks of Seoul 2014). The butterfly survey in NS was carried out on an asphalt road of about $2.5 \mathrm{~km}$ in length.

Ewha Womans University (EW: N $37^{\circ} 33^{\prime}$, E $126^{\circ} 56^{\prime}$ ) is located at Seodaemun-gu in Seoul. EW is located near to Mt. Bukak-san and Mt. An-san and its area is about 59 ha. EW is occupied mainly by buildings and paved roads. However, many gardens and natural forest remnants are managed. The major tree species are Zelkova serrate, Q. mongolica, and P. serrulata var. spontanea. The butterfly survey in EW was carried out on an asphalt road of about $2 \mathrm{~km}$ in length.

Bukseoul Dream Forest (BD: N 37 37', E $126^{\circ} 2^{\prime}$ ) is located at Gangbuk-gu and Seongbuk-gu in Seoul. BD is composed of Mt. Opae-san (123 m) and Byeoko-san $(135 \mathrm{~m})$ (Dream Forest 2014). The area of BD is about 66 ha. The major tree species are Q. acutissima, Pinus koraiensis, P. densiflora, and Robinia pseudoacacia. Large natural forest remnants remain and many gardens, a zoo, and a fountain were created for visitors. The butterfly survey in BD was carried out on a forest road and a dirt road of about $2 \mathrm{~km}$ in length.

Hongneung Forest (HF: N $37^{\circ} 35^{\prime}$, E $126^{\circ} 2^{\prime}$ ) is located at Dongdamun-gu in Seoul. HF is an experimental forest established by the Korea Forest Research Institute. The area of HF is about 41 ha. As of 2011, 20,000 plants in 157 different families and 2,035 species (1224 woody plants and 811 herbaceous plants) grow in the 41 ha forest (Cho et al. 2011). The major tree species are Alnus sibirica, Pinus rigida, and Robinia pseudoacacia. In some areas, Chamaecyparis pisifera and native trees including $P$. koraiensis and Abies holophylla have been planted in a multi-layered structure (Cho et al. 2011). The butterfly survey in HF was carried out on a forest road of about $2.5 \mathrm{~km}$ in length.

Gwangneung Forest (GF: N $37^{\circ} 44^{\prime}$, E $127^{\circ} 9^{\prime}$ ) is located at Pocheon-si in Gyeonggi-do, mid-western Korea. The natural forest is older than 100 years and composed mainly of Quercus serrata and Carpinus laxiflora (Lee et al. 1990). In South Korea, old deciduous forests (>100 years) such as GF are now rare. The butterfly survey in GF was conducted on a forest road of about $2 \mathrm{~km}$ in length, and included the 'long-term ecological research' (LTER) site of Korea Forest Research Institute.

\section{Butterfly surveys}

The survey was carried out by steadily walking along the survey routes and recording butterflies observed within a $10 \mathrm{~m}$ width along the routes, using the line transect method (Yamamoto 1975; Pollard and Yates 1993). This method has been extensively used to survey and monitor butterfly populations and communities (Honda and Kato 2005; Clark et al. 2007; Lee et al. 2014). The survey was conducted during the adult flight season, one time in April and October and twice from May to September 2012. In total, 12 surveys were carried out on each survey route. The butterfly census was carried out from 10:00 a.m. to 14:00 p.m. in clear weather without clouds. When identifying species by sight was difficult, the butterflies were caught using a net, identified, and released.

\section{Habitat type and niche breadth}

Butterflies were classified according to their habitat type and niche breadth. Habitat type was determined based on their larva habitats, such as grassland species (GL), forest edge species (FE), and forest interior species (FI). If a species was found in more than one habitat, the habitat was considered the one in which the species was most often observed. Niche breadth modified the method of Kitahara and Fujii (2005) and used diet breadth and voltinism (number of generations per year) to determine the niche breadth of each species. Diet breadth was classified into two categories based on range of host plant species by larvae. Feeding specialists are species feeding on plants of one plant genus, whereas feeding generalists are species feeding on more than one plant family. Univoltine species are classified as seasonal specialists, whereas multivoltine species are classified as seasonal generalists. If a species was a feeding specialist and seasonal specialist, it was considered as specialist species. If a species was a feeding generalist and seasonal generalist, it was considered as generalist species. Intermediate species was species with specialist in one of the two ecological traits. Habitats, voltinism, and the range of host plant species of all butterfly species in South Korea are shown in Kim et al. (2012).

\section{Land use analysis}

The land use data were collected from a 1:25,000 digital map from the National Geographic Information Institute. The patterns of the sounding environment of survey routes at the five study sites were analyzed using GIS. Previous studies suggested that circle of radius $5 \mathrm{~km}$ was most appropriate for considering the influence of the landscape on butterfly communities (Hanski and Kuussaari 1995; Bergman et al. 2004). However, 5 km radius in the urban green areas in Seoul included some natural forest. Thus, land use within a width of $3 \mathrm{~km}$ along the survey route was analyzed. The category of land use was clarified as seven types: paddy, field, park 
and green space, forest, urban area, road, and river and pond. Urban area includes residential area, industrial area, commercial area, and public facilities. Seven types of land use were modified by the percentage for analysis.

\section{Data analysis}

Species richness (number of species) and species diversity were evaluated by 'Estimate S' (Colwell 2005). Species richness was estimated by 'Jack 1' (Heltshe and Forrester 1983; Palmer 1990) and species diversity was estimated by the Shannon diversity index (Shannon and Weaver 1949). Species richness (Jack 1) and species diversity $\left(H^{\prime}\right)$ obtained from Estimate $\mathrm{S}$ were compared using a two-sample $t$-test (Zar 1999). The $X^{2}$ test was used to compare differences in species richness and density (abundance per $1 \mathrm{~km}$ transect) of habitat type and niche breadth between study sites (Zar 1999). The relationships between categories of land use and the butterfly index were examined using a Pearson correlation analysis. Correspondence analysis (CA) was used for ordination of the butterfly communities. CA ordination used 23 butterfly species that appeared at two or more of the study sites. The number of butterfly individuals was $\log$-transformed $(\ln N+1)$ to achieve a normal distribution of the data. The environmental factors used were percentage of paddy, field, park and green space, forest, urban area, road, and river and pond based on the GIS data. CA was conducted using PC-ORD (ver. 5.17) (McCune and Mefford 1999). Statistical analyses were performed using STATISTICA ver. 8.0 (StatSoft Inc. 2004).

\section{Results}

In total, 1,281 butterflies belonging to 57 species were observed (Table 1). There were 316 individuals of 38 species in GF, 342 individuals of 20 species in BD, 340 individuals of 19 species in HF, 161 individuals of 18 species in NS, and 122 individuals of 15 species in EW. Density was highest in BD (14.25), followed by GF (13.17), HF (11.33) and NS (5.37), and was lowest in EW (5.08). Zizeeria maha was the most abundant species, with 301 individuals (23.5\% of all individuals). Pieris canidia (14.4\%), Pieris rapae (11.6\%), and Libythea lepita (10.4\%) were also abundant. However, Z. maha and $P$. rapae were not observed in GF.

When habitat type was considered (Figure 2), species richness and density in the four urban green areas differed significantly from those in GF (species richness: $\chi^{2}=8.92-17.54, d f=2, P=0.012-0.000$; density: $\chi^{2}=8.70-$ $18.52, d f=2, P=0.013-0.0001)$. When niche breadth was compared between study sites (Figure 3 ), species richness and density in the four urban green areas differed significantly from those in GF (species richness: $X^{2}=$
7.30-8.16, $d f=2, P=0.026-0.017$; density: $\chi^{2}=6.31-17.43$, $d f=2, \quad P=0.042-0.0002)$, except for species richness between EW and GF $\left(\chi^{2}=4.68, d f=2, P=0.096\right)$.

The comparison of species richness and (Jack 1) and species diversity $\left(H^{\prime}\right)$ using Estimate $\mathrm{S}$ are shown in Figure 4. Estimated species richness was highest in GF (58) and was lowest in EW (20). Estimated species richness in the four urban green areas was significantly lower than in GF $(t=3.87-5.04, d f=26, P<0.001)$. Estimated species richness was significantly different between EW and BD $(t=-2.37, d f=26, P=0.026)$ and EW and HF $(t=-2.10, d f=26, P=0.045)$. Species diversity was highest in GF (2.41) and lowest in BD (1.81). Species diversity in the four urban green areas was significantly lower than that in GF $(t=2.47-5.35, d f=26, P=0.02-<0.001)$, except for GF and EW $(t=1.128, d f=26, P=0.27)$. Also, species diversity was significantly different between NS and $\mathrm{BD}(t=-2.20, d f=26, P=0.037)$, EW and $\mathrm{BD}(t=3.40, d f=$ $26, P=0.002)$, and BD and HF ( $t=-3.19, d f=26, P=0.004)$.

The percentage of urban area in NS, EW, BD, and HF was over $70 \%$, whereas that of forest in NS, EW, BD, and HF was below 17\% (Table 2). The percentage of road in NS, EW, BD, and HF was over $5.1 \%$, whereas that of GF was $0.1 \%$. Butterfly species richness, and species richness and density of forest interior species and specialist species were positively correlated with paddy, field, and forest, whereas those of forest interior species and specialist species were negatively correlated with urban area and road (Table 3). Density of forest edge species was negatively correlated with park and green space. Species richness of intermediate species was positively correlated with paddy, field, and forest, whereas that of intermediate species was negatively correlated with urban area and road. Similarity relationships of the butterfly communities in the five study sites were visualized using CA ordination (Figure 5). Axis I (92\%) and Axis II (5\%) explained $97 \%$ of the total variation. Butterfly communities were separated along Axis I. The butterfly communities in the four urban green areas differed from that in GF and were more similar in BD, NS, and HF.

\section{Discussion}

Our data show that butterfly species richness was negatively correlated with increasing urbanization (urban area and roads), whereas it was positively correlated with paddy, field, and forest. Species richness and density of niche breadth and habitat type in the urban green areas differed mostly from those in GF, a natural forest. Species richness and density of forest interior species and specialist species were positively correlated with paddy, field, and forest.

In our study, 26 species, such as Parnassius stubbendorfii, Luehdorfia puziloi, Wagimo signatus, were observed only in GF. Among them, specialist species accounted for $57.7 \%$ and forest interior species accounted for $73.1 \%$. 
Table 1 Butterflies observed at five study sites

\begin{tabular}{|c|c|c|c|c|c|c|c|c|c|}
\hline Species & NS & EW & BD & $\mathrm{HF}$ & GF & Total & $\%$ & Habitat type & Niche breadth \\
\hline Parnassius stubbendorfii & & & & & $0.04(1)$ & $0.01(1)$ & 0.1 & $\mathrm{GL}$ & S \\
\hline Luehdorfia puziloi & & & & & $0.5(12)$ & $0.09(12)$ & 0.9 & $\mathrm{Fl}$ & s \\
\hline Papilio xuthus & $0.13(4)$ & $0.33(8)$ & $0.21(5)$ & $0.03(1)$ & & $0.14(18)$ & 1.4 & GL & G \\
\hline Papilio macilentus & & & & $0.07(2)$ & & $0.02(2)$ & 0.2 & $\mathrm{FE}$ & G \\
\hline Papilio bianor & $0.13(4)$ & $0.04(1)$ & & $0.07(2)$ & $0.13(3)$ & $0.08(10)$ & 0.8 & $\mathrm{Fl}$ & G \\
\hline Papilio maackii & & & & & $0.04(1)$ & $0.01(1)$ & 0.1 & $\mathrm{Fl}$ & G \\
\hline Pieris melete & $0.23(7)$ & $1.04(25)$ & $0.21(5)$ & $0.57(17)$ & $0.88(21)$ & $0.57(75)$ & 5.9 & FE & G \\
\hline Pieris canidia & $1.90(57)$ & & $1.17(28)$ & $3.10(93)$ & $0.25(6)$ & 1.39 (184) & 14.4 & FE & G \\
\hline Pieris rapae & $0.83(25)$ & $0.38(9)$ & $2.00(48)$ & $2.20(66)$ & & $1.12(148)$ & 11.6 & GL & G \\
\hline Anthocharis scolymus & $0.17(5)$ & & $0.21(5)$ & $0.53(16)$ & $0.08(2)$ & $0.21(28)$ & 2.2 & FE & 1 \\
\hline Colias erate & $0.10(3)$ & $0.21(5)$ & $0.38(9)$ & & & $0.13(17)$ & 1.3 & GL & G \\
\hline Spindasis takanonis & & $0.04(1)$ & & & & $0.01(1)$ & 0.1 & $\mathrm{FE}$ & S \\
\hline Coreana raphaelis & & & & & $0.04(1)$ & $0.01(1)$ & 0.1 & $\mathrm{Fl}$ & S \\
\hline Japonica lutea & & & & & $0.04(1)$ & $0.01(1)$ & 0.1 & $\mathrm{Fl}$ & S \\
\hline Antigius butleri & & & & & $0.04(1)$ & $0.01(1)$ & 0.1 & $\mathrm{Fl}$ & S \\
\hline Wagimo signatus & & & & & $0.04(1)$ & $0.01(1)$ & 0.1 & $\mathrm{Fl}$ & S \\
\hline Favonius orientalis & $0.13(4)$ & & & $0.10(3)$ & & $0.05(7)$ & 0.5 & $\mathrm{Fl}$ & S \\
\hline Favonius taxila & & & & & $0.13(3)$ & $0.02(3)$ & 0.2 & $\mathrm{Fl}$ & S \\
\hline Satyrium prunoides & & $0.04(1)$ & & & & $0.01(1)$ & 0.1 & FE & S \\
\hline Callophrys ferreus & $0.03(1)$ & & & $0.03(1)$ & & $0.02(2)$ & 0.2 & FE & I \\
\hline Rapala caerulea & $0.03(1)$ & & $0.13(3)$ & $0.17(5)$ & & $0.07(9)$ & 0.7 & FE & G \\
\hline Lycaena dispar & & $0.04(1)$ & & & & $0.01(1)$ & 0.1 & $\mathrm{GL}$ & I \\
\hline Lycaena phlaeas & & $0.08(2)$ & & & & $0.02(2)$ & 0.2 & $\mathrm{GL}$ & 1 \\
\hline Zizeeria maha & $0.90(27)$ & $0.67(16)$ & 7.38 (177) & $2.70(81)$ & & $2.28(301)$ & 23.5 & GL & I \\
\hline Cupido argiades & & $0.46(11)$ & $0.04(1)$ & $0.07(2)$ & & $0.11(14)$ & 1.1 & $\mathrm{GL}$ & G \\
\hline Tongeia fischeri & $0.03(1)$ & & $0.25(6)$ & $0.20(6)$ & $0.04(1)$ & $0.11(14)$ & 1.1 & GL & G \\
\hline Celastrina argiolus & $0.23(7)$ & & $1.08(26)$ & $0.83(25)$ & $0.08(2)$ & $0.45(60)$ & 4.7 & $\mathrm{FE}$ & G \\
\hline Libythea lepita & $0.07(2)$ & & $0.04(1)$ & $0.20(6)$ & $5.17(124)$ & $1.01(133)$ & 10.4 & $\mathrm{Fl}$ & S \\
\hline Parantica sita & & & & & $0.04(1)$ & $0.01(1)$ & 0.1 & $\mathrm{FE}$ & G \\
\hline Mycalesis francisca & & & & & $0.25(6)$ & $0.05(6)$ & 0.5 & FE & G \\
\hline Mycalesis gotama & & & & & $0.04(1)$ & $0.01(1)$ & 0.1 & $\mathrm{FE}$ & G \\
\hline Minois dryas & & & $0.17(4)$ & & & $0.03(4)$ & 0.3 & $\mathrm{GL}$ & I \\
\hline
\end{tabular}


Table 1 Butterflies observed at five study sites (Continued)

\begin{tabular}{|c|c|c|c|c|c|c|c|c|c|}
\hline Argynnis paphia & & & & & $0.33(8)$ & $0.06(8)$ & 0.6 & $\mathrm{FE}$ & $\bar{S}$ \\
\hline Argynnis laodice & & $0.04(1)$ & & & $0.04(1)$ & $0.02(2)$ & 0.2 & $\mathrm{GL}$ & S \\
\hline Argynnis ruslana & $0.27(8)$ & & $0.17(4)$ & $0.27(8)$ & $0.46(11)$ & $0.23(31)$ & 2.4 & $\mathrm{GL}$ & $\mathrm{S}$ \\
\hline Neptis sappho & & & $0.04(1)$ & & $0.08(2)$ & $0.02(3)$ & 0.2 & $\mathrm{FE}$ & G \\
\hline Neptis philyra & & & & & $0.25(6)$ & $0.05(6)$ & 0.5 & $\mathrm{Fl}$ & । \\
\hline Neptis philyroides & & & & & $0.17(4)$ & $0.03(4)$ & 0.3 & $\mathrm{Fl}$ & । \\
\hline Neptis speyeri & & & & & $0.21(5)$ & $0.04(5)$ & 0.4 & $\mathrm{Fl}$ & $\mathrm{S}$ \\
\hline Neptis alwina & & & & & $0.08(2)$ & $0.02(2)$ & 0.2 & $\mathrm{FE}$ & । \\
\hline Neptis thisbe & & & & & $0.04(1)$ & $0.01(1)$ & 0.1 & $\mathrm{Fl}$ & S \\
\hline Neptis ilos & & & & & $0.13(3)$ & $0.02(3)$ & 0.2 & $\mathrm{Fl}$ & $\mathrm{S}$ \\
\hline Chitoria ulupi & & & & & $0.88(21)$ & $0.16(21)$ & 1.6 & $\mathrm{Fl}$ & S \\
\hline Dilipa fenestra & & & & & $0.04(1)$ & $0.01(1)$ & 0.1 & $\mathrm{Fl}$ & S \\
\hline Hestina assimilis & & & & & $0.21(5)$ & $0.04(5)$ & 0.4 & $\mathrm{Fl}$ & I \\
\hline Sasakia charonda & & & & & $1.92(46)$ & $0.35(46)$ & 3.6 & $\mathrm{Fl}$ & S \\
\hline Sephisa princeps & & & & & $0.08(2)$ & $0.02(2)$ & 0.2 & $\mathrm{Fl}$ & । \\
\hline Vanessa cardui & & $0.58(14)$ & $0.17(4)$ & & & $0.14(18)$ & 1.4 & $\mathrm{GL}$ & G \\
\hline Vanessa indica & $0.10(3)$ & $0.13(3)$ & & & & $0.05(6)$ & 0.5 & $\mathrm{GL}$ & G \\
\hline Polygonia c-aureum & $0.03(1)$ & $1.00(24)$ & $0.17(4)$ & $0.03(1)$ & $0.04(1)$ & $0.23(31)$ & 2.4 & $\mathrm{GL}$ & । \\
\hline Burara aquilina & & & & & $0.04(1)$ & $0.01(1)$ & 0.1 & $\mathrm{Fl}$ & । \\
\hline Lobocla bifasciata & & & & $0.03(1)$ & & $0.01(1)$ & 0.1 & $\mathrm{FE}$ & । \\
\hline Satarupa nymphalis & & & & & $0.04(1)$ & $0.01(1)$ & 0.1 & $\mathrm{Fl}$ & $\mathrm{S}$ \\
\hline Daimio tethys & & & $0.13(3)$ & & & $0.02(3)$ & 0.2 & $\mathrm{FE}$ & । \\
\hline Erynnis montanus & & & $0.04(1)$ & & $0.25(6)$ & $0.05(7)$ & 0.5 & $\mathrm{FE}$ & $\mathrm{S}$ \\
\hline Thymelicus leoninus & & & & & $0.04(1)$ & $0.01(1)$ & 0.1 & $\mathrm{GL}$ & I \\
\hline Parnara guttata & $0.03(1)$ & & $0.29(7)$ & $0.13(4)$ & & $0.09(12)$ & 0.9 & $\mathrm{GL}$ & G \\
\hline Species richness & 18 & 15 & 20 & 19 & 38 & 57 & & & \\
\hline Density & $5.37(161)$ & $5.08(122)$ & $14.25(342)$ & $11.33(340)$ & $13.17(316)$ & $9.70(1281)$ & & & \\
\hline
\end{tabular}

Density indicate abundance per $1 \mathrm{~km}$ transect. The numbers in parentheses indicate abundance. See text for classification methods of habitat type and niche breadth. Study sites, NS: Namsan Park, EW: Ewha Womans University, BD: Bukseoul Dream Forest, HF: Hongneung Forest, GF: Gwangneung Forest. Habitat type, GL: grassland species, FE: forest edge species, Fl: forest interior species. Niche breadth, S: specialist species, I: intermediate species, G: generalist species. 
Table 2 Area (ha) and percentage of land use categories within the range of $\mathbf{3} \mathbf{~ k m}$ from study route of five study sites

\begin{tabular}{lllllll}
\hline Land use category & Unit & NS & EW & BD & HF & GF \\
\hline Paddy & ha & 0 & 0 & 0 & 0 & 141.5 \\
& $\%$ & 0 & 0 & 0 & 0 & 4.5 \\
Field & ha & 0 & 0 & 0.8 & 0.5 & 231.7 \\
& $\%$ & 0 & 0 & 0 & 0 & 7.4 \\
Park and & ha & 161.4 & 151.7 & 152.8 & 151.2 & 130.1 \\
green space & $\%$ & 4.1 & 4.3 & 4.1 & 3.9 & 4.1 \\
Forest & ha & 392.5 & 485.9 & 625.9 & 403.9 & 2524.1 \\
& $\%$ & 9.9 & 13.8 & 16.9 & 10.3 & 80.5 \\
Urban & ha & 2855.7 & 2523 & 2681.7 & 3038.9 & 80.7 \\
& $\%$ & 71.8 & 71.7 & 72.3 & 77.4 & 2.6 \\
Road & ha & 282 & 254 & 188.2 & 284.5 & 2.3 \\
& $\%$ & 7.1 & 7.2 & 5.1 & 7.2 & 0.1 \\
River and pond & ha & 285.9 & 102.3 & 59.9 & 46.6 & 25.2 \\
& \% & 7.2 & 2.9 & 1.6 & 1.2 & 0.8 \\
\hline
\end{tabular}

Clark et al. (2007) showed that rare and specialized species were most affected by urbanization and the decrease in butterfly species richness was associated with increased urban areas. Butterfly species richness was lower as urban intensity became higher along an urban-rural gradient
(Ruszczyk and De Araujo 1992; Fortunato and Ruszczyk 1997; Stefanescu et al. 2004; Posa and Sodhi 2006; Clark et al. 2007). Our results were consistent with those previous studies. Stefanescu et al. (2004) found loss of butterfly species richness was detectable in highly humanized landscapes although good butterfly habitats predominated along transects. The patterns of land use in urban areas contributed to declines in butterfly species richness (Casner et al. 2014). Posa and Sodhi (2006) reported that urbanization was detrimental to forest butterfly species. Butterflies specialized in both host plants and timing of reproduction disappeared with declining richness across sites 2.9-4.5 times faster than did generalists and less restricted specialists (Clark et al. 2007). Our study showed that species richness and density of specialist species in the four urban green areas were significantly lower versus those of specialist species in GF. Butterfly species with few larval host plants are more at risk than generalists, which can use a wider range of resources. Specialist species will be restricted to areas where they can lay their eggs because they are highly dependent on their host plants for survival. Six of seven Neptis species were found only in GF and they are specialist species and forest interior species except for Nepis alwina. Nepits species may be vulnerable in urban green area. One cause of the decline of Nepits species in urban green areas may be loss
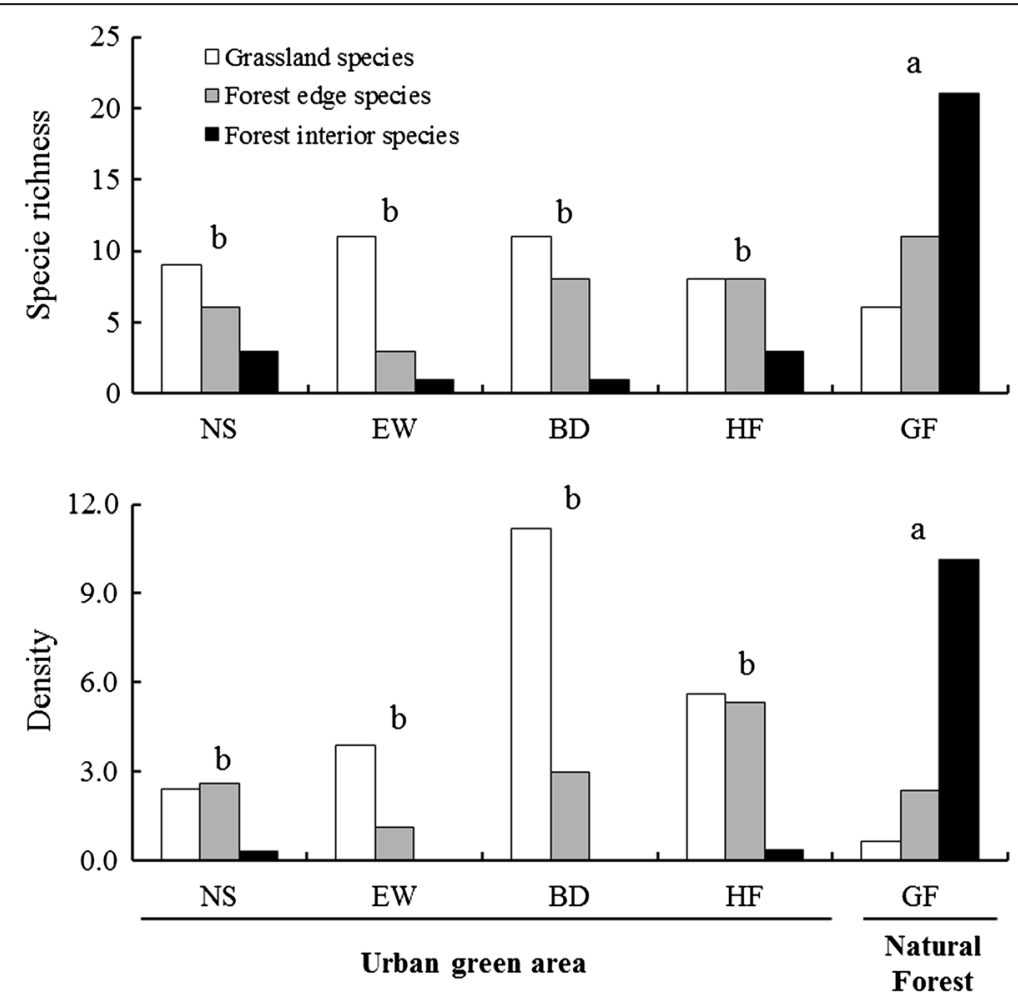

Figure 2 Species richness and density of habitat type of butterfly observed at five study sites. Species richness (number of species) and density (abundance per 1-km transect) of habitat type (forest interior species, forest edge species, and grassland species) of butterfly observed at five study sites. Different letters above the bars indicate significant difference. 

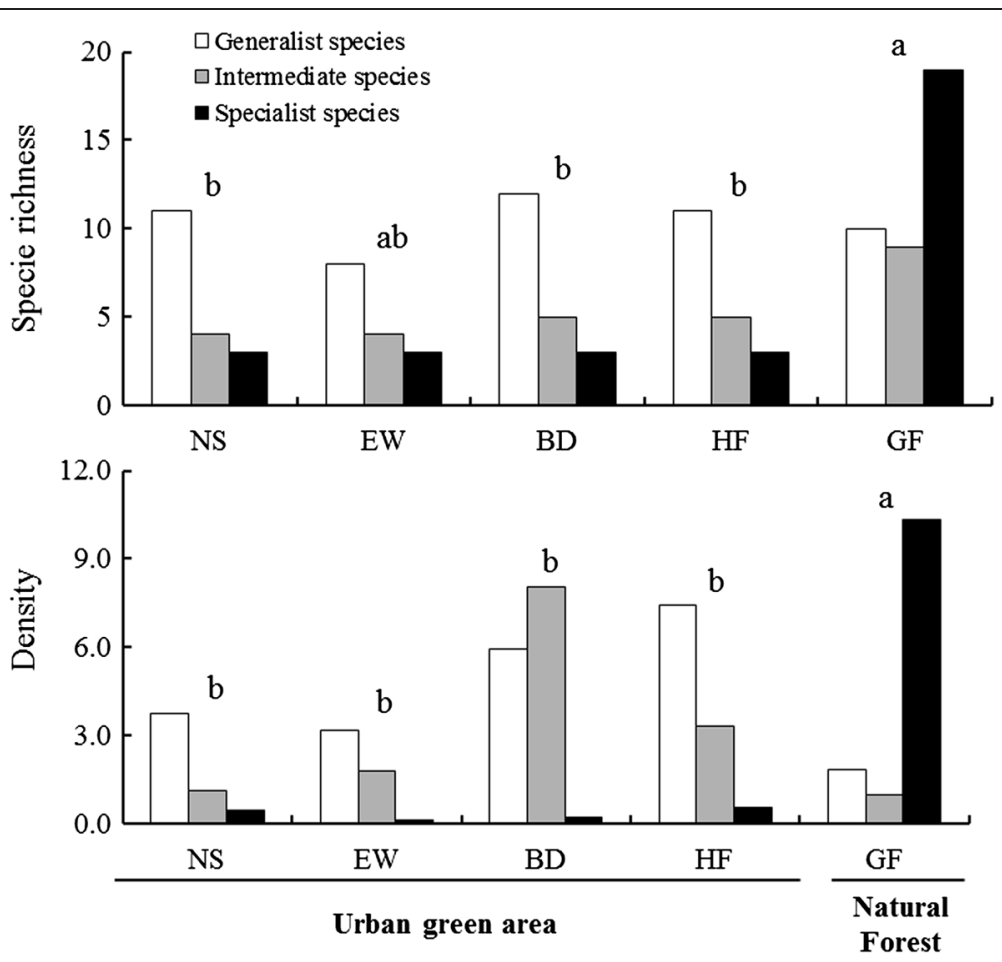

Figure 3 Species richness and density of niche breadth of butterfly observed at five study sites. Species richness (number of species) and density (abundance per 1-km transect) of niche breadth (specialist species, intermediate species, and generalist species) of butterfly observed at five study sites. Different letters above the bars indicate significant difference.
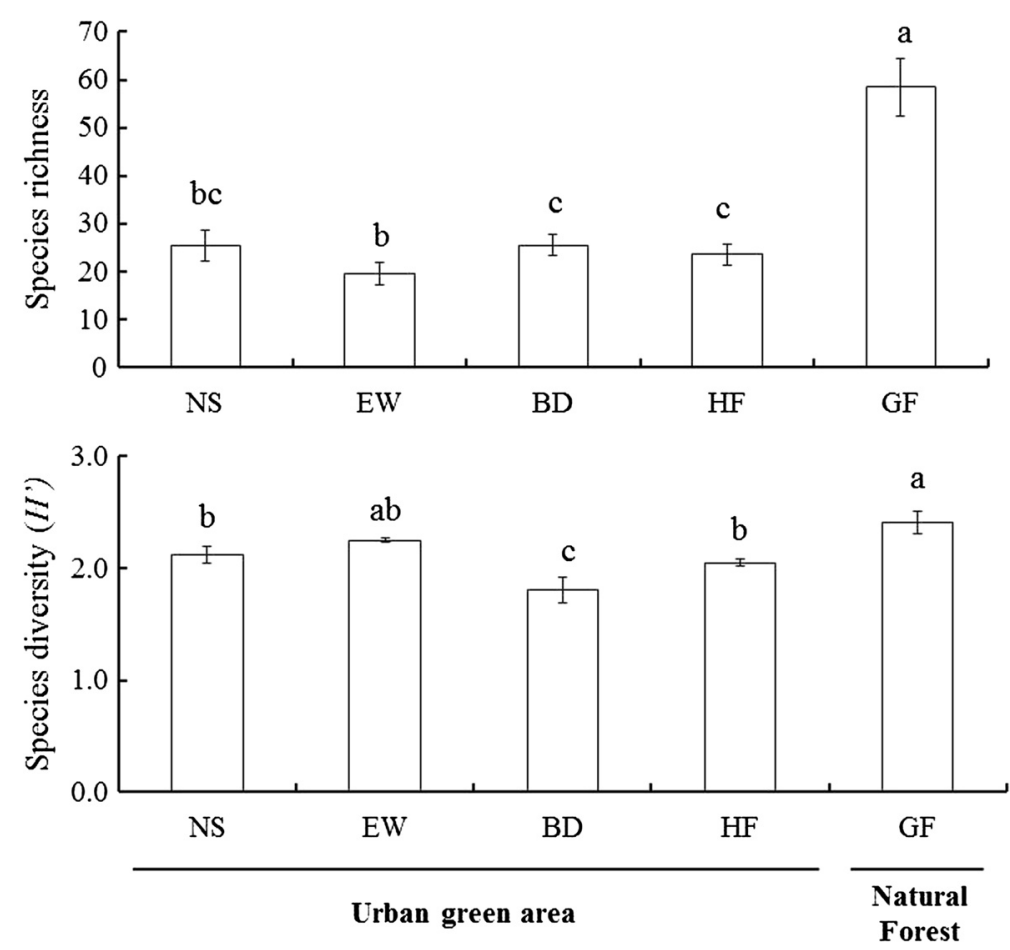

Figure 4 Estimation of species richness (Jack 1$)$ and species diversity $\left(H^{\prime}\right)$ of butterfly at five study sites. Species richness and species diversity were obtained using Estimate S (Colwell et al. 2004). Different letters above the error bars indicate significant difference. The error bars indicate one standard deviation. 
Table 3 Pearson correlation coefficient between butterfly index and land use category within the range of 3 km from study route of five study sites

\begin{tabular}{|c|c|c|c|c|c|c|c|}
\hline Community index & Paddy & Field & Park and green space & Forest & Urban area & Road & River and pond \\
\hline \multicolumn{8}{|l|}{ Species richness } \\
\hline All species & $0.98^{* *}$ & $0.98^{* *}$ & 0.02 & $0.98^{* *}$ & $-0.97^{* *}$ & $-0.97^{* *}$ & -0.45 \\
\hline \multicolumn{8}{|l|}{ Habitat type } \\
\hline Forest interior species & $0.99^{* *}$ & $0.99 * *$ & 0.07 & $0.99^{* *}$ & $-0.99 * *$ & $-0.93^{*}$ & -0.37 \\
\hline Forest edge species & 0.72 & 0.72 & -0.43 & 0.72 & -0.69 & -0.79 & -0.51 \\
\hline Grassland species & -0.79 & -0.79 & 0.40 & -0.74 & 0.75 & 0.65 & 0.25 \\
\hline \multicolumn{8}{|l|}{ Niche breadth } \\
\hline Specialist species & $1.00^{* * *}$ & $1.00^{* * *}$ & 0.17 & $1.00^{* * *}$ & $-1.00^{* * *}$ & $-0.96^{*}$ & -0.42 \\
\hline Intermediate species & $0.97^{* *}$ & $0.97^{* *}$ & 0.02 & $0.97^{* *}$ & $-0.96^{*}$ & $-0.97^{* *}$ & -0.57 \\
\hline Generalist species & -0.15 & -0.14 & -0.66 & -0.14 & 0.17 & -0.03 & 0.02 \\
\hline \multicolumn{8}{|l|}{ Density } \\
\hline All species & 0.42 & 0.43 & -0.32 & 0.47 & -0.40 & -0.61 & -0.76 \\
\hline \multicolumn{8}{|l|}{ Habitat type } \\
\hline Forest interior species & $1.00^{* * *}$ & $1.00^{* * *}$ & 0.14 & $0.99^{* *}$ & $-1.00^{* * *}$ & $-0.95^{*}$ & -0.41 \\
\hline Forest edge species & -0.18 & -0.17 & $-0.97^{* *}$ & -0.21 & 0.24 & 0.17 & -0.28 \\
\hline Grassland species & -0.56 & -0.56 & -0.14 & -0.50 & 0.56 & 0.31 & -0.27 \\
\hline \multicolumn{8}{|l|}{ Niche breadth } \\
\hline Specialist species & $1.00^{* * *}$ & $1.00^{* * *}$ & 0.13 & $0.99^{* *}$ & $-0.99^{* *}$ & $-0.95^{*}$ & -0.41 \\
\hline Intermediate species & -0.39 & -0.39 & -0.13 & -0.32 & 0.39 & 0.12 & -0.36 \\
\hline Generalist species & -0.66 & -0.66 & -0.71 & -0.66 & 0.70 & 0.57 & -0.18 \\
\hline
\end{tabular}

${ }^{*} P<0.05 ;{ }^{* *} P<0.01 ;{ }^{* *} P<0.001$. 


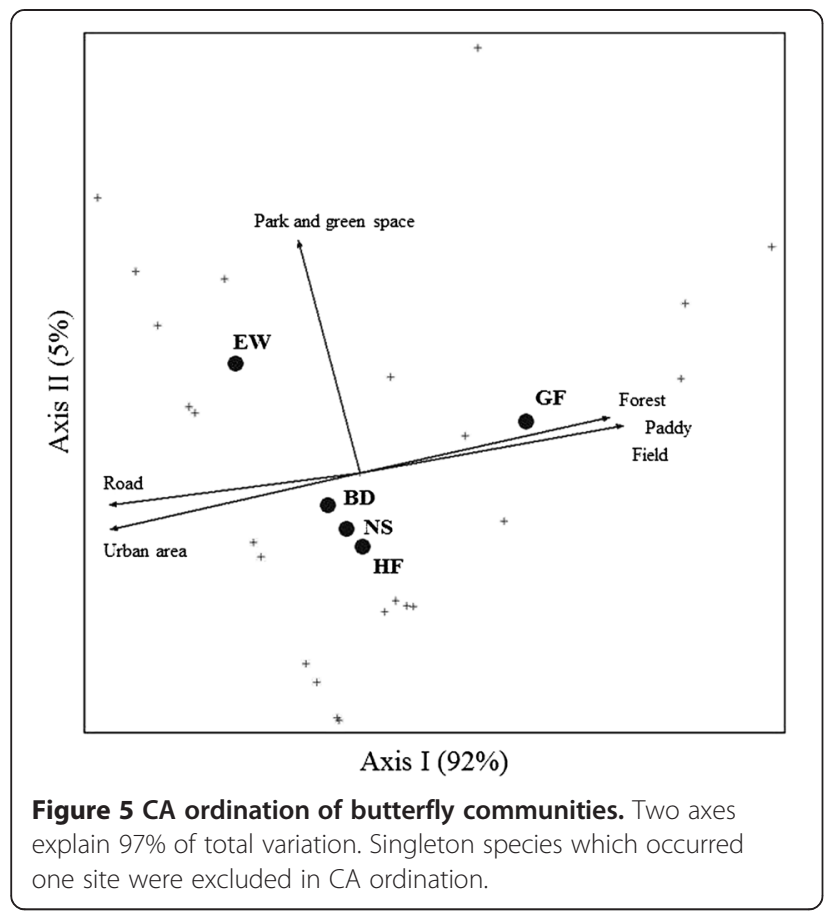

of their larval host plants. Host plants of $N$. philyroides and N. speyeri are Carpinus cordata,Carpinus laxiflora, and Corylus heterophylla var. thunbergii (Kim and Seo 2012). These trees were not located in urban green areas, Korea (S-SK, personal observation). In GF, Carpinus cordata and Carpinus laxiflora are one of dominant trees (Lee et al. 1990). Host plants of N. thisbe and N. ilos are Quercus serrate and Quercus sp., respectively. These trees were located in urban areas. However, Two Neptis species were not found in urban green areas because they may favour low temperature habitats as forests compared with urban green areas (S-SK, personal observation).

In Osaka City, Japan, the numbers of butterfly species richness decreased from 50 in the early 1930s to 30 in the late 1980s because of the effects of urbanization (Imai 1998). Imai (1998) found that the decrease in species richness was remarkable in univoltine and/or forestpreferring species groups. Similarly, the proportion of generalist species richness increased with the developing urban areas in Tsukuba City, Japan (Kitahara and Fujii 1994, 1997). Our study found that the proportion of generalist species richness was more than $53 \%$ in the urban green areas. Additionally, some studies have shown that butterfly species richness peaked in sites with intermediate disturbances (Blair and Launer 1997; Blair 2001; Hogsden and Hutchinson 2004). Our study was conducted relatively large urban green areas and a natural forest in a rural area. Further study will need to study butterflies in urban green areas of various sizes in order to clarify the effect of intermediate disturbances.
Responses to the effects of urbanization differ among butterflies. Hiura (1973) found that forest species, sedentary butterflies, univoltine species, and wild-tree feeders were greatly influenced by urbanization. In Osaka City, Japan, drastic decreases in species richness were first observed in Hesperiidae between the 1930s and 1950s, second in Satyridae between the 1950s and 1960s, and third in Pieridae between the 1970s and 1980s (Imai 1998). Species richness in Hesperiidae was most markedly decreased in urban green areas, suggesting that this family is most sensitive to habitat isolation through urbanization, except highly migratory species, such as Parnara guttata (Imai 2004). In our study, Hesperiid species richness in the urban green areas was lower than that in GF. $P$. guttata was observed in NS, BD, and HF. However, Burara aquiline, Satarupa nymphalis, and Thymelicus leoninus were only observed in GF. These three species have been not observed in urban green areas in Korea (Kim et al. 2012). The response of Satyridae to urbanization showed a similar trend with that of Hesperiidae (Imai 2004). In our study, Mycalesis francisca and M. gotama were absent from the four urban green areas. However, the Korean distribution of the two species has broadened recently because of vegetation changes due to the success of reforestation (Kwon et al. 2012). Ishii et al. (1991) noted that Satyrid species disappear in urban green areas because they are mainly forest species, sedentary butterfly, and wild-tree feeders. Furthermore, Ishii (2001) showed that the percentages of bamboo-grass feeders, univoltine species, and non-migratory species were lower in urban parks compared with those in Satoyama. However, urban landscapes often have high species diversity, even including rare and threatened species (Shepherd 1994). Spindasis takanonis, an endangered Korean species, has been observed in the Hongneung Forest (Lee and Kwon 2012). This species lives mainly at the forest edge of urban and suburban areas in Korea. Lee and Kwon (2012) suggested that there is a case that urban green areas play important roles in the conservation of rare species.

In contrast, Hiura (1973) suggested that grassland species, cultivated plant feeders, multivoltine species, and migratory species will be remained in urban areas. Papilionidae, Pieridae, and Lycaenidae did not differ greatly between urban and suburban areas, and species richness of the three families increased from small urban green areas to large urban green areas (Imai 1998). In the present study, P. rapae, Papilio xuthus, and Z. maha were observed in the four urban green areas, but not GF. These three species are included in the 'strong' species for urbanization suggested by Hiura (1973). P. rapae was one of the most common species in urban green areas in Korea (CML, personal observation). Kocher and Williams (2000) noted that $P$. rapae was found in higher abundance in disturbed than that in undisturbed habitats. Takami 
et al. (2004) suggested that $P$. rapae could tolerate high temperatures caused by urban warming, and could use ephemeral habitats within cities, such as gardens and vacant land. $P$. xuthus was observed in all urban parks of various sizes (2.0-126 ha) in and around Osaka City, Japan (Imai 1998). P. xuthus did not decrease during the grassland removal and deforestation period in Kanazawa Castle Park, Japan (Ohwaki et al. 2008). It is thought that $P$. xuthus may tolerate disturbances by humans because this species has a high dispersal ability and a broad range of food resources. In the present study, Z. maha was the most dominant species. Ishii et al. (1991) showed that $Z$. maha was a dominant species in urban parks, which had large areas of grassland. In Korea, this species was often observed on grassland in the urban green areas (JWR, personal observation). The host plant of Z. maha is Oxalis corniculata, which is very common weed in urban area and cities and is located nationally in Korea (Lee 2013). Recently, Z. maha seems to be abundant because this species can now survive the milder winters due to climate change in the central part of Korea (CML, unpublished data).

Butterfly species richness decreased as the distance from the nearest mountain increased (Imai 1998). In the present study, EW was located near to Mt. Ansan and Mt. Inwansan. However, butterfly species richness was lowest there, in this study. The butterfly community in EW was separated from that in BK, HF, and NS. Although there were gardens and trees, the butterfly community seemed to be negatively influenced by the many buildings and asphalt roads. The relationships between butterfly diversity and the influence of built elements have been shown to be significant (Lizée et al. 2012). In our study, butterfly species richness, species richness of forest interior species, specialist species, and intermediate species and density of forest interior species and specialist species were negatively correlated with urban area and road.

\section{Conclusion}

In conclusion, our results suggest that the decrease in paddy, field, and forest associated with the increased urban area and road negatively influenced species composition and changed butterfly communities. Biodiversity in urban area decreases due to the increase of areas such as residential area, industrial area, and commercial area associated with the decrease of natural environment. Urban areas homogenize the physical environment to satisfy the needs of humans. Therefore, improving biodiversity is important for comfortable human living in urban areas. We propose to plant trees and make biotope or butterfly garden in urban parks, factory sites or universities in order to increase biodiversity.

\section{Competing interests}

The authors declare that they have no competing interests.

\section{Authors' contributions}

CML designed the experiment for the present study, wrote the manuscript, and surveyed butterfly. JWP and T-SK analyzed the data. S-SK, JWR, SJJ, and SKL surveyed butterfly. All authors read and approved the final manuscript.

\section{Author details}

${ }^{1}$ Division of Forest Ecology, Korea Forest Research Institute, 57 Hoegi-ro, Dongdaemun-gu, Seoul 130-712, Republic of Korea. ${ }^{2}$ Department of Landscape Architecture, Catholic University of Daegu, 13-13 Hayang-ro, Hayang-eup, Gyeongsan-si, Daegu 712-702, Republic of Korea. ${ }^{3}$ Division of Forest Insect Pests and Diseases, Korea Forest Research Institute, 57 Hoegi-ro, Dongdaemun-gu, Seoul 130-712, Republic of Korea. ${ }^{4}$ Research Institute for East Asian Environment and Biology, 293-27 Amsa 3 dong, Gangdong-gu, Seoul 143-203, Republic of Korea. ${ }^{5}$ Ewha Womans University Natural History Museum, 52 Ewhayeodae-gil, Seodaemun-gu, Seoul 120-750, Republic of Korea. ${ }^{6}$ Department of Biology, Kyung Hee University, 26 Kyungheedae-ro, Dongdaemun-gu, Seoul 130-701, Republic of Korea. 'Entomology program, Department of Agricultural Biotechnology, Seoul National University, Seoul, Republic of Korea.

Received: 29 July 2014 Accepted: 16 December 2014

Published online: 03 January 2015

\section{References}

Bergerot B, Fontaine B, Julliard R, Baguette M (2011) Landscape variables impact the structure and composition of butterfly assemblages along an urbanization gradient. Landscape Ecol 26:83-94

Bergman KO, Askling J, Ekberg O, Ignell H, Wahlman H, Milberg P (2004) Landscape effects on butterfly assemblages in an agricultural region. Ecography 27:619-628

Blair RB (2001) Birds and butterflies along urban gradients in two ecoregions of the U.S. In: Lockwood JL, McKinney ML (eds) Biotic Homogenization. Kluwer, New York, pp 33-56

Blair RB, Launer AE (1997) Butterfly diversity and human land use: species assemblages along an urban gradient. Biol Conserv 80:113-125

Casner Kl, Forister ML, O'brien JM, Thorne J, Waetjen D, Shapiro AM (2014) Contribution of urban expansion and a changing climate to decline of a butterfly fauna. Conserv Biol DOl:10.1111/cobi.12241

Cho JH, Park C-R, Kim S-K (2011) Hongneung Forest. Korea Forest Research Institute News 11-09

Clark PJ, Reed JM, Chew FS (2007) Effects of urbanization on butterfly species richness, guild structure, and rarity. Urban Ecosyst 10:321-337

Colwell RK (2005) Estimate S: Statistical estimation of species richness and shared species from sample. Version 7.5 User's Guide and application published at: [Cited 8 March 2005] Available from URL: http://viceroy.eeb.uconn.edu/ estimates

Colwell RK, Mao CX, Chang J (2004) Interpolating, extrapolating, and comparing incidence-based species accumulation curves. Ecology 85:2717-2727

Dover J, Settele J (2009) The influences of landscape structure on butterfly distribution and movement: a review. J Insect Conserv 13:3-27

Dream Forest (2014) Dream Forest. Available at: http://dreamforest.seoul.go.kr

Fortunato L, Ruszczyk A (1997) Communities of fruit-feeding butterflies in urban and extraurban green areas of Uberlandia, Minas Gerais. Rev Bras Biol 57:79-87

George SL, Crooks KR (2006) Recreatin and large mammal activity in an urban nature reserve. Biol Conserv 133:107-117

Grimm NB, Faeth SH, Golubiewski NE, Redman CL, Wu J, Bai X, Briggs JM (2008) Global change and the ecology of Cities. Sciences 319:756-760

Hamer AJ, McDonnell MJ (2008) Amphibian ecology and conservation in the urbanizing world: a review. Biol Conserv 141:2432-2449

Hanski I, Kuussaari M (1995) Butterfly metapopulation dynamics. In: Cappuccino N, Price PW (eds) Population dynamics: new approaches and synthesis.. Academic Press, London, pp 149-171

Heltshe JF, Forrester NE (1983) Estimating species richness using the jackknife procedure. Biometrics 39:1-12

Hiura I (1973) Butterflies across the Sea. Soju-Shobo, Tokyo (in Japanese)

Hogsden KL, Hutchinson TC (2004) Butterfly assemblages along a human disturbance gradient in Ontario, Canada. Can J Zool 82:739-748 
Honda K, Kato Y (2005) Biology of Butterflies. University of Tokyo Press, Tokyo, p 626pp

Imai C (1998) An ecological study for enrichment of biological diversity in urban areas. Jpn J Environ Entomol Zool 9:55-73

Imai C (2004) Ecological approaches for improvement of biological diversity in Osaka City, central Japan. Osaka and its Technol 44:13-22

Ishii M (2001) Studies on insects and their habitats in the Satoyama in a broader sense. Jpn J Environ Entomol Zool 12:187-193

Ishii M, Yamada M, Hirowatari T, Yasuda T (1991) Diversity of butterfly communities in urban parks in Osaka Prefecture. Jpn J Environ Entomolo Zool 3:183-195

Kim DS (2008) Geomorphological background and urbanized feature of Seoul. Ph.D. Thesis of Korea National University of Education. 180 pp

Kim S-S, Lee CM, Kwon T-S, Joo HZ, Sung JH (2012) Korean butterfly atlas 1996-2011. Research Note 461, Korea Forest Research Institute, Korea Disabled Human Good Life Pub. Co, Seoul, in Korean

Kim S-S, Seo YH (2012) Life histories of Korean butterflies. Publishing Sagyejel, Paju, $538 \mathrm{pp}$

Kitahara M, Fujii K (1994) Biodiversity and community structure of temperate butterfly species within a gradient of human disturbance: an analysis based on the concept of generalist vs. Specialist strategies. Res Popul Ecol 36:187-199

Kitahara M, Fujii K (1997) An island biogeographic approach to the analysis of butterfly community patterns in newly designed parks. Res Popul Ecol 39:23-35

Kitahara M, Fujii K (2005) Analysis and understanding of butterfly community composition based on multivariate approaches and the concept of generalist/specialist strategies. Entomol Sci 8:137-149

Kocher SD, Williams EH (2000) The diversity and abundance of North American butterflies vary with habitat disturbance and geography. J Biogeogr 27:785-794

Kwon T-S, Lee CM, Kim S-S, Sung JH (2012) Distribution change of Korean butterflies 1938-2011. Research Note 472. Korea Forest Research Institute. Samsung Adcom Pub. Co, Seoul, in Korean

Lee CM, Ishii M (2009) Species diversity of ground beetle assemblages at urban greeneries in southern Osaka, central Japan. Jpn J Environ Entomol Zool 20:47-58

Lee CM, Kwon T-S (2012) Characterization of the butterfly community of a fragmented urban forest, Hongneung Forest. Korean J Appl Entomol 51:317-323

Lee CM, Kwon T-S (2013) Community structure, species diversity of insects (ants, ground beetle), and forest health in the Hongneung Forest. J Korean For Soc 102:97-106

Lee CM, Kwon T-S, Kim S-S, Sohn J-D, Lee B-W (2014) Effects of forest degradation on butterfly communities in the Gwangneung forest. Entomol Sci 17:293-301

Lee DH (2013) Korean wild flowers. Ibirak Pub. Co, Seoul, p 581 pp

Lee KJ, Jo JC, Lee BS, Lee DS (1990) The structure of plant community in Kwangnung Forest (I). J Korean For Soc 79:173-186

Lee S-K (2003) The change of migration in the Seoul metropolitan region, 1990-2003. MD. Department of Geography Education Graduate school of Education Sungshin Women's university

Lizée M-H, Manel S, Mauffrey JF, Tatoni T, Deschamps-Cottin M (2012) Matrix configuration and patch isolation influences override the species-area relationship for urban butterfly communities. Landscape Ecol 27:159-169

Mauro DD, Dietz T, Rockwood L (2007) Determining the effect of urbanization on generalist butterfly species diversity in butterfly gardens. Urban Ecosyst 10:427-439

McCune B, Mefford M (1999) PC-ORD. Multivariate analysis of ecological data. Version 4.0. MjM Software Design, Gleneden Beach, OR

McKinney ML (2002) Urbanization, biodiversity, and conservation. Bioscience $52: 883-890$

McKinney ML (2006) Urbanization as a major cause of biotic homogenization. Biol Conserv 127:247-260

McKinney ML (2008) Effects of urbanization on species richness: a review of plants and animals. Urban Ecosyst 11:161-176

Motegi N, Yanai S (2005) A study on the characteristics of bird distribution in rooftop vegetation in Tokyo Ward. Jpn Inst Landscape Architecture 68:597-600

Niemelä J, Kotze JD, Venn S, Penev L, Stoyanov I, Spence J, Hartley D, de Oca EM (2002) Carabid beetle assemblages (Coleoptera, Carabidae) across urban-rural gradients: an international comparison. Landscape Ecol 17:387-401

Ohwaki A, Tanabe S-I, Nakamura K (2008) Effects of anthropogenic disturbances on the butterfly assemblage in an urban green area: the changes from 1990 to 2005 in Kanazawa Castle Park, Japan. Ecol Res 23:697-708

Osawa S, Katsuno T (2005) Distribution pattern of amphibian on rural landscape in the middle reaches of the Oita river, northeast Kyusyu. Jpn Inst Landscape Architecture 68:563-566
Palmer MW (1990) The estimation of species richness by extrapolation. Ecology 71:1195-1198

Parks of Seoul (2014) Seoul metropolitan government. Available at: http://parks. seoul.go.kr/eng/common/park_info/introduce.jsp?park_id=namsan

Pollard E, Yates TJ (1993) Monitoring butterflies for ecology and conservation. Conservation biology series. Chapman \& Hall, Institute of Terrestrial Ecology \& Nature Conservation Committee, London, United Kingdom

Posa MRC, Sodhi NS (2006) Effects of anthropogenic land use on forest birds and butterflies in Subic Bay, Philippines. Biol Conserv 129:256-270

Rubèn OA, lan MF (2009) Living in the big city: effects of urban land-use on bird community structure, diversity, and composition. Landsc Urban Plan 90:189-195

Ruszczyk A, De Araujo AM (1992) Gradients in butterfly species diversity in an urban area in Brazil. J Lepid Soc 46:255-264

Shannon CE, Weaver W (1949) A mathematical theory of communication. University of Illinois press, Urbana, IL, 117pp

Shepherd PA (1994) A review of plant communities of derelict land in the city of Nottingham, England and their value for nature conservation. Memorabilia Zoologica 49:129-137

StatSoft, Inc. (2004) Statistica forWindows. Version 6. Statsoft Inc., Tulsa, OK

Stefanescu C, Herrando S, Páramo F (2004) Butterfly species richness in the north-west Mediterranean Basin: the role of natural and human-induced factors. J Biogeogr 31:905-915

Takami Y, Koshio C, Ishii M, Fujii H, Hidaka T, Shimizu I (2004) Genetic diversity and structure of urban population of Pieris butterflies assessed using amplified fragment length polymorphism. Mol Ecol 13:245-258

Thomas CD (1995) Ecology and conservation of butterfly metapopulations in the fragmented British landscape. Chapman and Hall, London

Yamaguchi T (2005) Influence of urbanization on ant distribution in parks of Tokyo and Chiba City, Japan II. Analysis of species. Entomol Sci 8:17-25

Yamamoto Y (1975) Notes on the methods of belt transect census of butterflies. J Fac Sci Hokkaido Univ Ser VI Zool 20:93-116

Zar JH (1999) Biostatistical Analysis, 4th edn. Prentice Hall International, INC., Upper Saddle River, NJ

\section{Submit your manuscript to a SpringerOpen ${ }^{\circ}$ journal and benefit from:}

- Convenient online submission

- Rigorous peer review

- Immediate publication on acceptance

- Open access: articles freely available online

- High visibility within the field

- Retaining the copyright to your article

Submit your next manuscript at $>$ springeropen.com 